\title{
Dietary education and iron deficiency anaemia in the inner city
}

F Childs, A Aukett, P Darbyshire, S Ilett, L N Livera

Northern Birmingham Community NHS

Trust, Child Health Medical Services

F Childs

A Aukett

L N Livera

Birmingham

Children's Hospital

NHS Trust:

Department of

Community

Paediatrics

S Ilett

Department of Haematology

P Darbyshire

Correspondence to: Dr F Childs, Child Health Department, Worcestershire Community Healthcare NHS Trust, Isaac Maddox House, Shrub Hill Road, Worcester WR4 9RW.

Accepted 26 October 1996

\begin{abstract}
Objectives-To assess if a dietary health education programme could be used within existing health resources to reduce the incidence of iron deficiency anaemia in an inner city population.

Design-Prospective cohort study.

Setting-Inner city areas of west and south Birmingham.

Subjects-A total of 1000 children recorded on the child health computer register.

Intervention-Children were recruited at birth and randomised into control and intervention groups. Families in the intervention group received specific health education information at key ages by face to face contact using a range of materials. The control group received standard health education as delivered by the health visitors at the time.

Main outcome measures-Haemoglobin estimation and iron content of the diet at 18 months of age.

Results-A total of 455 children completed the study. Sixty nine $(27 \%)$ of the control group and $55(28 \%)$ of the intervention group were anaemic as defined by haemoglobin less than $110 \mathrm{~g} / \mathrm{l}$. There was no difference in the iron content of the diets offered to the two groups of children.

Conclusion-In this deprived population we have shown no reduction in anaemia using a targeted nutritional programme and have highlighted the difficulties in conducting health education programmes within the scope of current health resources.

(Arch Dis Child 1997;76:144-147)
\end{abstract}

Keywords: iron deficiency anaemia; primary preventative measures; health education.

Iron deficiency is an important public health issue for children as it is the most common nutritional disorder in early childhood. The prevalence of iron deficiency anaemia in preschool children has been estimated as between 10 and $30 \% \cdot{ }^{1-4}$ It is more common in children from some ethnic minority groups (notably Asian and African Caribbean) and children disadvantaged by poor socioeconomic circumstances.

The effects of iron deficiency in children under 5 years have been widely reported. Effects on psychomotor development are well recognised ${ }^{15-7}$ and there is evidence that these adverse consequences may not be fully revers- ible with treatment. ${ }^{8}$ This may be linked with a critical point in early childhood where lack of iron may have a permanent deleterious effect. ${ }^{9}$

The natural history of iron deficiency anaemia in young children is still not clearly delineated, but its high prevalence and its relationship with adverse developmental outcome suggests that primary preventative measures need to be emphasised, rather than secondary prevention (screening programmes). Previous studies have shown that health education programmes (when combined with screening) can have some success in primary care. ${ }^{10}$ Our study attempted to determine whether a nutritional education programme using existing health care resources (with health visitors as the educators) could effectively reduce the prevalence of iron deficiency anaemia in inner city toddlers.

\section{Subjects and methods}

SUBJECTS

The study group was drawn from two inner city areas of west and south Birmingham, both areas of high socioeconomic deprivation. A small pilot sample was taken before the study started to assess the prevalence of anaemia in the toddler population of the areas. Twenty five of $73(34 \%)$ children of a sample group aged between 18 and 24 months were shown to have haemoglobin $<110 \mathrm{~g} / \mathrm{l}$.

Newborn infants were identified with the use of the child health computer child register. A total of 1000 infants was recruited at 6 weeks of age after interviews with the parent(s) had been carried out by the project health visitor. Informed written consent was obtained from the parent(s). Information was collected on socioeconomic factors and birth and family details. Children were randomised into control and intervention groups. Approval for the study was granted by the ethical committees of Central and West Birmingham Health $\mathrm{Au}-$ thorities.

\section{METHODS}

The control group received from their own health visitors the districts' current practice on nutritional education. There was no uniformity in nutritional education at the time of the study and this varied in consistency and with individual practice between districts. Interviews were carried out at around 3, 6, and 9 months of age, when data were collected on feeding practices.

The parent(s) of the children in the intervention group received additional specific information at these contacts. They listened to 
Table 1 Characteristics of children in study

\begin{tabular}{|c|c|c|}
\hline & $\begin{array}{l}\text { No (\%) recruited } \\
(n=1000)\end{array}$ & $\begin{array}{l}\text { No (\%) completing project } \\
(n=455)\end{array}$ \\
\hline \multicolumn{3}{|l|}{ Ethnic group } \\
\hline White European & $186(19)$ & $50(11)$ \\
\hline Asian & $712(71)$ & $357(78)$ \\
\hline African Caribbean & $76(8)$ & $30(7)$ \\
\hline Other & $26(3)$ & $18(4)$ \\
\hline \multicolumn{3}{|l|}{ Mother's education } \\
\hline None or primary school only & $310(31)$ & $160(35)$ \\
\hline \multicolumn{3}{|l|}{ Mother's age (years) } \\
\hline$<20$ & $280(28)$ & $82(18)$ \\
\hline$>38$ & $240(24)$ & $26(6)$ \\
\hline \multicolumn{3}{|l|}{ Father's occupation by social class } \\
\hline I and II & $100(10)$ & $48(11)$ \\
\hline IV, V, or unclassified & $500(50)$ & $276(61)$ \\
\hline \multicolumn{3}{|l|}{ Family size } \\
\hline Average No of children & 2.5 & 2.5 \\
\hline More than 3 children & $220(22)$ & $104(23)$ \\
\hline
\end{tabular}

audio tapes in relevant languages with the health visitor; they then had the opportunity and were encouraged to discuss the specific information on diet and iron at the time of the interview (with an interpreter if needed) and were given culturally appropriate health education leaflets. This additional information was aimed at three specific age groups: $3-4$ months, 4-6 months, and 9-12 months. Its theme was to promote the correct use of breast milk or fortified infant feeds throughout the first year of life and to encourage good weaning diets containing an appropriate intake of iron rich foods and vitamin C.

A sample group of 20 families was visited during the study period to ensure that the health education materials had been received and understood appropriately.

At 18 months the children and parent(s) were seen for a final interview by the project health visitor; growth and dietary data were collected and a capillary blood sample was taken for a full blood count and serum ferritin measurement.

The families and general practitioners of all children completing the study were contacted with the blood test results. General practitioners were requested to treat anaemic children (as defined by haemoglobin $<110 \mathrm{~g} / \mathrm{l}$ ) with a two month course of iron by mouth and measurements were repeated by the study team. Children with haemoglobin $<80 \quad \mathrm{~g} / \mathrm{l}$ were referred to a paediatrician for evaluation. Children were excluded from the study if they were noted to be taking iron at the 18 month interview.

DIET AND FEEDING PRACTICES

Data on dietary practices were collected by 24 hour and seven day diet recall methods. These involved questionnaires on foodstuffs offered to the children. For 24 hour recall, data were collected on foods and drinks taken at mealtimes and other daytime 'snacks'. Data on seven day diet recall were obtained by listing specific foodstuffs. Parents/carers were then questioned on the regularity of consumptionfor example, daily, three times weekly, once weekly, or not at all. On the basis of the diet recalled we calculated individual food scores from 1 to 7 with the consumption of foods in the following groups: (1) meat/fish; (2) eggs; (3) cereals/bread; (4) green vegetables; (5) len- tils (dahl); (6) beans/non-green vegetables; and (7) fresh fruit/fruit juice.

The emphasis on determining a 'good' diet in terms of iron containing foods was based on the consumption of haem iron, foods containing non-haem iron and foodstuffs rich in vitamin $\mathrm{C}$ as an adjunct to iron absorption.

An adequate iron food score for data from 24 hour recall was defined as an intake of more than four of the foodstuff groups listed. For the seven day recall data an intake of more than four of the foodstuff groups at least three times in the week was classed as adequate.

The data were entered onto a database and analysed using Epi-Info. ${ }^{11}$ The $\chi^{2}$ test was used to analyse specified groups within the study.

\section{Results}

Although 1000 children were recruited, losses were high over the period of the study due particularly to population mobility and families not cooperating after initial recruitment. In addition, staff shortages and high health visitor caseloads limited the ability of the health visitors to sustain contact with non-attending families. A total of 455 children $(45.5 \%$ of those recruited) completed the study fully.

Table 1 shows the characteristics of the study families recruited and completing the study. No difference between the control and intervention families was noted nor were there marked changes between those recruited and completing the study. In both groups $>70 \%$ of the families were Asian. A large number of families were disadvantaged by maternal education status and environmental and social factors. Study losses were higher in those families who had younger and older mothers $(<20$ years and $>38$ years, respectively). A total of $22 \%$ of both groups had families of four or more children.

Table 2 shows the results of the blood tests. A full blood count (FBC) was measured on a capillary sample. Anaemia was defined as haemoglobin $<110 \mathrm{~g} / \mathrm{l}$. Capillary blood was also taken for ferritin assay, but samples proved unsatisfactory for measuring iron status. The families of those children with haemoglobin $<110 \mathrm{~g} / 1$ were contacted for a repeat FBC after a request to their general practitioner to prescribe iron by mouth for two months. Repeat tests were obtained on 97 children $(71 \%)$. An increase in haemoglobin of $>10 \mathrm{~g} / 1$ was noted in 55 children ( $57 \%$ ), with a rise of $>20 \mathrm{~g} / \mathrm{l}$ in $26(27 \%)$. Five children were identified as having blood indices suggestive of $\beta$ thalassaemia trait and referred for further evaluation. Although compliance with treatment with iron by mouth was poor $(<40 \%$ completed the course as requested), we feel the results reflect iron deficiency as the cause of anaemia.

The data show that $69(27 \%)$ of the control and $55(28 \%)$ of the intervention groups had haemoglobin $<110 \mathrm{~g} / \mathrm{l}$. There was no significant difference between the two study groups $(\mathrm{p}=0.9)$.

The prevalence of anaemia was higher in children of Asian and African Caribbean origin, reflecting observations from previous 
Table 2 Children with anaemia (haemoglobin < $110 \mathrm{~g} / \mathrm{l}$ ); values are number (\%) of children

\begin{tabular}{llll}
\hline & Control group $(n=257)$ & Intervention group $(n=198)$ & $p$ Value \\
\hline $\begin{array}{l}\text { Total } \\
\text { Ethnic group }\end{array}$ & $69(27)$ & $55(28)$ & 0.9 \\
$\quad$ White European & $5(19)[\mathrm{n}=26]$ & $3(11)[\mathrm{n}=27]$ & 0.65 \\
$\quad$ Asian & $57(27)[\mathrm{n}=207]$ & $46(30)[\mathrm{n}=152]$ & 0.65 \\
$\quad$ African Caribbean & $5(29)([=17]$ & $3(25)[\mathrm{n}=12]$ & 0.87 \\
$\quad$ Other & $2(28)[\mathrm{n}=7]$ & $3(43)[\mathrm{n}=7]$ & 1.0 \\
$\begin{array}{l}\text { Total mean haemoglobin } \\
\quad(\mathrm{g} / \mathrm{l})\end{array}$ & 116 & 116 & \\
Total mean MCV (fl) & 69 & 70 & \\
\hline
\end{tabular}

$\mathrm{MCV}=$ mean corpuscular volume.

Table 3 Anaemia and social variables (haemoglobin $<110 \mathrm{~g} / \mathrm{l}$ )

\begin{tabular}{|c|c|c|c|c|c|}
\hline & \multicolumn{2}{|c|}{ Control group $(n=257)$} & \multicolumn{2}{|c|}{$\begin{array}{l}\text { Intervention group } \\
(n=198)\end{array}$} & \multirow[b]{2}{*}{$p$ Value } \\
\hline & No (\%) & Total & No (\%) & Total & \\
\hline \multicolumn{6}{|l|}{ Mother's education } \\
\hline None or primary school & $31(33)$ & 93 & $23(47)$ & 68 & 0.95 \\
\hline More than primary school & $36(23)$ & 159 & $32(24)$ & 130 & 0.79 \\
\hline No data & - & 5 & - & - & - \\
\hline \multicolumn{6}{|l|}{ Social class } \\
\hline I, II, and III & $25(28)$ & 89 & $19(22)$ & 86 & 0.45 \\
\hline $\mathrm{IV}, \mathrm{V}$, and $\mathrm{U}$ & $44(26)$ & 168 & $3632)$ & 112 & 0.34 \\
\hline \multicolumn{6}{|l|}{ Birth order } \\
\hline Firstborn & $22(25)$ & 89 & $17(20)$ & 83 & 0.63 \\
\hline Other rank & $46(27)$ & 168 & $38(33)$ & 115 & 0.37 \\
\hline
\end{tabular}

Table 4 Infant feeding practices; values are number (\%) of children

\begin{tabular}{lll}
\hline & Control group $(n=257)$ & Intervention group $(n=198)$ \\
\hline Breast feeding & & \\
At 3 months & $65(23)$ & $30(15)$ \\
At 6 months & $31(12)$ & $11(6)$ \\
At 9 months & $6(2)$ & $6(3)$ \\
Introduction of pasteurised cows' milk & & \\
At 3 months & $20(8)$ & $9(4)$ \\
At 6 months & $100(39)$ & $123(57)$ \\
\hline
\end{tabular}

Table 5 Dietary data; values are number (\%) of children

\begin{tabular}{llll}
\hline & Control group $(n=257)$ & Intervention group $(n=198)$ & $p$ Value \\
\hline $\begin{array}{l}24 \text { hour diet recall } \\
\begin{array}{l}\text { Food score }>4 \\
\text { day diet recall }\end{array}\end{array}$ & $88(34)$ & $75(38)$ & 0.48 \\
Food score $>4$ & $209(81)$ & $161(81)$ & 0.9 \\
\hline
\end{tabular}

Table 6 Twenty four hour diet data for social variables: food score $>4$; values are number (\%) of children

\begin{tabular}{llll}
\hline & Control group $(n=257)$ & Intervention group $(n=198)$ & $p$ Value \\
\hline Mother's education & & & \\
$\quad$ None or primary school & $20(21)[\mathrm{n}=93]$ & $17(25)[\mathrm{n}=68]$ & 0.74 \\
$\quad \begin{array}{l}\text { More than primary school } \\
\text { No data }\end{array}$ & $65(40.8)[\mathrm{n}=159]$ & $58(44.6)[\mathrm{n}=130]$ & 0.6 \\
Social class & $-[\mathrm{n}=5]$ & - & - \\
$\quad$ I, II, and III & $41(46)[\mathrm{n}=89]$ & $34(39)[\mathrm{n}=86]$ & 0.47 \\
$\quad$ IV, V, and U & $47(28)[\mathrm{n}=168]$ & $41(37)[\mathrm{n}=112]$ & 0.16 \\
Birth order & $33(37)(\mathrm{n}=89)$ & $35(42)(\mathrm{n}=83)$ & 0.59 \\
$\quad$ Firstborn & $55(33)(\mathrm{n}=168)$ & $40(34.7)(\mathrm{n}=115)$ & 0.81 \\
$\quad$ Other rank & &
\end{tabular}

reports. ${ }^{24}$ There was no significant difference in the prevalence of anaemia between the control and intervention groups when children were matched for ethnicity and social variables (mother's education level, social class as identified by husband's or partner's occupation and birth rank) (table 3).

FEEDING PRACTICES

Data on feeding practices were collected at the 3,6 , and 9 month interviews. Table 4 gives the data for breast feeding practices and data on the age of introduction of fresh pasteurised whole cows' milk for children completing the study. The proportion of children breast fed was low compared with current recorded UK practice. A total of $57 \%$ of children in the intervention group and $39 \%$ of those in the control group were recorded as taking fresh cows' milk at 6 months. This is despite advice contained in the additional health intervention material to continue breast feeding or to use fortified infant feeds, as well as standard advice given to parents of children in the control group by health professionals.

\section{DIETARY DATA}

Table 5 shows diet scores for 24 hour and seven day diet recall methods. There was no significant difference in the diets offered to the two groups. There is a poor correlation between the iron food scores recalled by the two methods; neither is sensitive as a predictor for anaemia (sensitivities 65 and $26 \%$, respectively).

Twenty four hour diet recall has been used to match adequate food scores to social variables (table 6). As with the prevalence of anaemia, we noted no significant difference between the control and intervention groups. A significant difference was noted within groups when looking at maternal education, however. Children whose mothers had been educated beyond primary school level showed better food scores $(p$ $=0.01$ in the intervention group and $p=0.002$ in the control group). This was not reflected by a significant difference in the level of anaemia (table 3).

\section{GROWTH DATA}

There were no differences in mean weight, height, or mid upper arm circumference at age 18 months between the control and intervention groups.

\section{Discussion}

The results of this study show that anaemia remains a common problem in inner city Birmingham and that the dietary health intervention methods used were ineffective in reducing its prevalence. 'Contamination' of the control group by cross filtering of the more specific health information delivered to the intervention group seems unlikely given the overall high prevalence of anaemia.

Despite the emphasis on good infant feeding practice, few mothers breast fed their infants beyond 3 months of age and significant numbers of infants received cows' milk before the age of 1 year. The level of fresh cows' milk intake is comparable with other UK reports of infants' liquid diets ${ }^{12}$ and shows that this problem still needs to be addressed.

Twenty four hour dietary data suggest that the diets of the toddler population studied were poor in iron rich foods. The seven day dietary scores suggest a satisfactory dietary intake of iron, but inaccurate recall may bias these observations. This illustrates the difficulties in qualitative determinants of dietary intake and how this correlates with anaemia status. This is important because assessing satisfactory nutritional intake is often based on such methods. 
The additional dietary educational measures were limited to the use of existing health visiting resources to deliver more targeted nutritional advice in three specific sessions. We acknowledge that this had no impact in reducing anaemia in this study population, who may be vulnerable because of the influences of cultural practices and disadvantage.

This project was not designed to determine the actual consumption of iron by quantitative assessment. We recognise that many factors influence the availability of iron in the diet and assessment is difficult. In addition, food fads and food refusal are common in this age and these influence the actual iron intake when compared with the diet offered. Feedback from the project health visitors showed this to be a common observation of parents/carers in both study groups. We were unable to determine how this may have influenced the results obtained, but this emphasises the need for further evaluation of the relationship between iron deficiency anaemia and qualitative and quantitative assessments of dietary iron intake.

Iron deficiency anaemia in early childhood may have deleterious consequences, many of which can be reversed with treatment; however, an adverse outcome for cognitive function may not be fully reversible. Such developmental effects may be more closely linked with the onset of anaemia in early life and the duration of anaemia. ${ }^{9}$ More effective primary preventative measures are needed. The most effective means of preventing iron deficiency anaemia should be through dietary education, emphasising optimum feeding regimens and adequate weaning and toddler diets, with the use of fortified foodstuffs where appropriate (for instance, fortified infant feeds and cereals).

Effective public nutritional education programmes have been reported from the USA. ${ }^{13}{ }^{14}$ The most successful have included the free provision of fortified formula and foods. ${ }^{15}$ A recent study in Birmingham has shown that the provision of a follow on formula milk was effective in preventing anaemia in children between 7 and 18 months of age ${ }^{16}$ and shows that this approach could also be successful in the UK.

Much nutritional education is on an individual basis, as used in this study. Although other studies have reported success in raising immediate dietary awareness with such methods, ${ }^{10}$ we found them to be ineffective in promoting changes in feeding practices in the families recruited. A follow up study of children screened for iron deficiency anaemia who received similar dietary advice has also questioned its longer term effectiveness. ${ }^{17}$

Many factors are important in the success or failure of such approaches. Health educators should understand iron nutrition and deficiency in young children, and the influence of differing cultural practices and economic constraints. They must acknowledge how the receipt and implementation of such information by individuals will be influenced by conflicting advice from other family members (particularly when these are the relevant care givers) and friends. We speculate that it might be more successful to focus on 'group' health education using community groups, local media, dietetic support, and more involvement from families themselves.

\section{Key messages}

- The prevalence of iron deficiency anaemia in young children is high, particularly those disadvantaged by poor socioeconomic circumstances and in children of certain ethnic groups

- Iron deficiency adversely effects children's cognitive development-this effect may not be fully reversible with treatment

- Standard nutritional educational packages were ineffective in reducing the level of anaemia in this study

- Community based approaches to prevention should be combined with secondary prevention by screening and treatment of populations at risk

The project was financed by the Wolfson Foundation via a grant to the University of Birmingham. Haematological investigations were performed in the haematology department, Birmingham Children's Hospital.

Marzia Esmail and Yasmin Meghani were the project health visitors; interpreter and clerical help was supplied by the West and Central Birmingham Community Health Services. We thank all of these people, and also acknowledge the major contribution of the health visitors at Lansdowne, Soho, Edward Road, Small Heath, and Farm Road Child Health Clinics, Birmingham.

1 Aukett MA, Parkes YA, Scott PH, Wharton BA. Treatment with iron increases weight and psychomotor development. Arch Dis Child 1986;61:849-57.

2 Ehrhardt P. Iron deficiency in young Bradford children from different ethnic groups. BMF 1986;292:90-3.

3 James J, Evans J, Male P, Pallister C, Hendrikz J, Oakhill A. Iron deficiency in inner city pre-school children: development of a general practice screening programme. $\mathcal{F} \mathrm{R}$ Coll Gen Pract 1988;38:250-2.

4 James J, Laing G. Iron deficiency anaemia. Current Paediatrics 1994;4:33-7.

5 Lozoff B, Brittenham GM, Viteri F, Wolf AW, Urratia JJ. The effects of short term iron therapy on developmental deficits in iron deficient anaemic children. $\mathcal{f}$ Pediatr 1982;100:351-7.

6 Idjradinata P, Pollit E. Reversal of developmental delay in ron deficient infants treated with iron. Lancet 1993;341:14.

7 Oski FA, Honig AS. The effect of therapy on the developmental scores of iron deficient infants. 7 Pediatr 1978;92:21-5.

8 Lozoff B, Jimenez EJ, Wolf AW. Long term developmental outcome of infants with iron deficiency. $N$ Engl $7 \mathrm{Med}$ 1991;325:687-94

9 Parkes YA, Wharton BA. Iron deficiency and the brain. Acta Paediatr Scand Suppl 1989;361:71-7.

10 James J, Lawson P, Male P, Oakhill A. Preventing iron deficiency in preschool children by implementing an educational and screening programme in an inner city practice. BMF 1989;299:838-40.

11 Dean AG, Dean JA, Coulomber D, et al. Epi-Info version 6; a word processing database and statistical programme for epidemiology on microcomputers. Atlanta, Georgia: Centers for Disease Control and Prevention, 1994

2 White A, Freeth S, O’Brien M. Infant feeding 1990. London: HMSO, 1992

13 Yip R, Walsh K, Goldfarb H. Declining childhood anaemia prevalence in a middle class setting: a pediatric success story. Pediatrics 1987;80:330-4.

14 Yip R, Binkin N, Fleshwood L, Trowbridge F. Declining prevalence of anaemia among low income children in the United States. FAMA 1987;258:1619-23.

15 Miller V, Swaney S, Deinard A. Impact of the WIC Program on the iron status of infants. Paediatrics 1985;75:100-5.

16 Daley A, MacDonald A, Aukett A, et al. Prevention of anaemia in inner city toddlers by an iron supplemented cows' milk formula. Arch Dis Child 1996;75:9-16.

17 James J, Laing G, Logan S. Changing pattern of iron deficiency anaemia in the second year of life. BMF 1995;311:230. 